\title{
A clinical comparison of nano-crystalline hydroxyapatite (Ostim) and autogenous bone graft in the treatment of periodontal intrabony defects
}

\author{
Mohammad-Taghi Chitsazi ${ }^{1}$, Adileh Shirmohammadi ${ }^{2}$, Masoumeh Faramarzie ${ }^{3}$, Reza Pourabbas ${ }^{4}$, Amir \\ naser Rostamzadeh ${ }^{5}$
}

\footnotetext{
${ }^{1}$ Associated Professor, Periodontics Department, Tabriz Dental Faculty

${ }^{2}$ Associated Professor, Head of Periodontics Department, Tabriz Dental Faculty

${ }^{3}$ Assistant Professor, Periodontics Department, Tabriz Dental Faculty

${ }^{4}$ Associated Professor, Periodontics Department, Tabriz Dental Faculty

${ }^{5}$ Periodontist, Department, Tabriz Dental Faculty
}

\section{Correspondence:}

Periodontics Department

Tabriz Dental Faculty

Golgasht St., Tabriz, Iran

shirmohamadia@yahoo.com

Received: 08/04/2010

Accepted: 04/06/2010

Chitsazi MT, Shirmohammadi A, Faramarzie M, Pourabbas R, Rostamzadeh A. A clinical comparison of nano-crystalline hydroxyapatite (Ostim) and autogenous bone graft in the treatment of periodontal intrabony defects. Med Oral Patol Oral Cir Bucal. 2011 May 1;16 (3):e448-53. http://www.medicinaoral.com/medoralfree01/v16i3/medoralv16i3p448.pdf

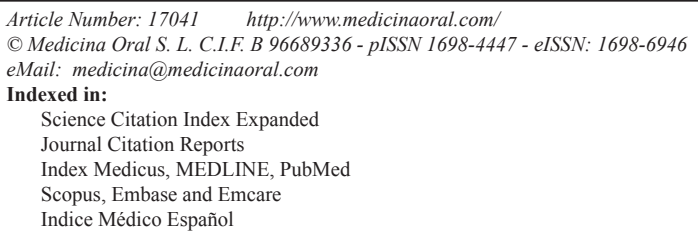

\begin{abstract}
Objectives: The aim of the present study was to evaluate the efficacy of autogenous bone graft (ABG) and nanocrystalline hydroxyapatite (Ostim) in the management of human intrabony periodontal defects.

Study Design: Twenty-four similar two and three wall intrabony periodontal defects with $\geq 5 \mathrm{~mm}$ probing depths and $\geq 3 \mathrm{~mm}$ depths of intrabony component in 12 healthy patients were selected. One defect in each subject was treated with ABG (ABG group) and the contralateral one with ABG and Ostim (Ostim group). Plaque index (GI), gingival index (PI), clinical probing depth (CPD), clinical attachment level (CAL), gingival margin level, bone fill, crestal resorption and defect resolution were measured at baseline and during reentry surgery after 6 months. Wilcoxon signed-rank test and Mann-Whitney U test were used to analyze the data.

Results: Groups showed statistically significant improvements in soft and hard tissue parameters after 6 months except in gingival margin level and crestal level. However, the between-group differences after 6 months were not statistically significant with regard to soft and hard tissue measurements.

Conclusion: Within the limits of this study, both treatments resulted in marked clinical improvement, and Ostim treatment seemed to be effective in the treatment of two\&three-wall intrabony defects as well as autogenous bone graft.
\end{abstract}

Key words: Intrabony defect, bone graft, periodontal regeneration, autogenous bone graft. 


\section{Introduction}

Intrabony defects represent a major challenge for the clinician. These defects often require access flap surgery alone or in association with bone-respective techniques (1). However, despite a successful etiologic therapy, the ultimate goal of periodontal treatment is the regeneration of periodontal tissues lost during the disease process. A variety of treatment modalities including the use of autogenous bone grafts and bone substitutes materials $(2,3)$,guided tissue regeneration (GTR) with the use of barrier membranes (4), and growth factors (5) have been proposed to promote the regeneration of periodontal tissues.

Two systematic reviews $(6,7)$ summarizing the clinical outcomes following application of specific biomaterials as bone-replacement grafts in the treatment of deep intrabony defects indicated that bone replacement grafts and bone substitutes were significantly more effective than open flap debridement in improving attachment levels and in reducing probing depths (PDs). However, differences in clinical attachment level (CAL) gains varied considerably among the different biomaterials used; because of this heterogeneity in the results among studies, the investigators (6) were unable to draw conclusions about the use of specific graft biomaterials. Until now, autogenous bone is recognized as the gold standard. Bone cell precursors in the graft provide osteoinductive properties without adverse immunological response (8). Nevertheless, autografts increase the morbidity and are limited in availability. These considerations have led to an increased exploration of alternative bone substitute materials. These materials are supposed to be biocompatible, noninfectious, and nonantigenic. Although most are not considered to be osteoinductive, they should at least be osteoconductive (9).

A synthetic nano-crystalline hydroxyapatite (ncHA) bone substitution material has been successfully introduced for the augmentative treatment of space-maintaining bone defects after defect fractures and cystectomies without revealing negative side effects $(10,11)$. Although this ncHA material is different from microcrystalline bone substitution materials regarding solubility, its chemical composition corresponds to that of bone mineral. The particle size was reported to be $18 \mathrm{~nm}$ in average, which allows for an accelerated substitution by vital bone (12). This ncHA material (Ostims, Heraeus Kulzer, Hanau, Germany) has been used in a recently published animal study in adult domestic pigs for observation of the regenerative potential in bony defects. This animal study examined the de novo bone formation in bony defects following the insertion of autogenous bone alone versus an injectable nanoparticle hydroxyapatite alone and in combination with $25 \%$ autogenous bone. The regenerative potentials of the tested materials were compared with each other. Microradiography indicated mineralization rates in the 2 bone substitute groups that were not significantly lower than those found in the autogenous bone group. Histologically, there was suitable osseointegration and osteoconduction of the used material. Complete resorption of the nanoparticle hydroxyapatite had taken place after 12 weeks. It can be concluded that the evaluated nanoparticular hydroxyapatite met the clinical requirements for a bone substitute material within the limits of this experimental setting (13). In contrast, microcrystalline hydroxyapatite was shown to be ensheathed by newly formed bone and partly replaced by it, but resorbed very slowly, as shown in animal experiments after 9 months (14) or in clinical studies after a 6 -month observation period $(15,16)$.

Because no reports on the clinical use of nano-crystalline hydroxyapatite (Ostim) for treatment of periodontal infrabony defects are available as yet, the purpose of the present study was to compare the clinical outcomes obtained by ostim with those obtained by ABG as a therapy for human intrabony defects.

\section{Materials and Methods}

\section{Study population and experimental design}

In this split-mouth study, 12 patients with a mean age of 38 years, who had referred to the Periodontics Department of Tabriz Dental Faculty for the treatment of periodontal disease, were included.

Patients were selected according to following criteria: (1) absence of relevant medical conditions that contraindicated periodontal surgery; (2) no use of antibiotics during the previous 6 months; (3) no pregnancy or lactation; (4) optimal compliance (no missed treatment appointments), as assessed during cause-related therapy; (5) good oral hygiene standards, defined as a full-mouth plaque score $\geq 20 \%$ (17); and (6) presence of at least on pair of matched two or three-wall periodontal infrabony defect with a $P D \geq 5 \mathrm{~mm}$ and a radiographic depth of the defect $\geq 3 \mathrm{~mm}$. Patients with teeth exhibiting furcation involvement, inadequate endodontic treatment, or overhanging margins were excluded from the study. None of the patients was a smoker.

The study design was approved by the Ethics Committee and supported by the Research Deputy of Tabriz Medical Sciences University. The nature of this investigation was explained in detail, and the patients signed an informed consent form.

Each patient first received cause-related therapy consisting of scaling and root planing, motivation, and oral hygiene instructions. Four weeks after the completion of initial therapy, re-evaluation examination was performed. At the time of surgery plaque index (GI) and gingival index (PI) (18) were recorded, and clinical parameters were measured with a Williams periodontal probe (PWD, Hu-Friedy Immunity, USA) from a fixed point using customized acrylic stents to prevent 
angulation and positioning errors. All baseline clinical parameters were obtained on the day of the surgery by one examiner, who was blind to the type of treatment. Final parameters were taken 6 months postoperatively by the same examiner, again blind to the method of the study. A calibration exercise was performed to obtain acceptable intra-examiner reproducibility for probing depth and recession of the gingival margin. Prior to the study and after 6 months, five patients, each with ten teeth with probing depth of $>5 \mathrm{~mm}$ on at least one aspect of each tooth, were used for calibration. The examiner evaluated the patients on two occasions, $48 \mathrm{~h}$ apart. Calibration was accepted if $>90 \%$ of the recording could be reproduced within a $1.0-\mathrm{mm}$ difference. The following soft tissue measurements were included:

1. Clinical probing depth (CPD): free gingival margin to the base of the pocket.

2. Clinical attachment level (CAL): inferior margin of the stent to the base of the pocket.

3. Gingival margin level (ST-GM): inferior margin of the stent to the free gingival margin. Differences between the baseline measurements and those obtained 6 months after surgery demonstrated gingival recession.

\section{Surgical procedure}

All surgical procedures were performed by the same surgeon. Prior to surgery, patients were instructed to rinse with $0.12 \%$ chlorhexidine gluconate for $30 \mathrm{sec}$ onds. Anesthesia was obtained by administration of $2 \%$ lidocaine 1:80,000 epinephrine. Buccal and lingual intrasulcular incisions were performed, and mucoperiosteal flaps on the facial and lingual aspects of each tooth, segment, or area involved were reflected. Incisions were designed to preserve as much of the interproximal tissue as possible. Soft tissue debridement was performed as well as thorough scaling and root planing of the exposed root surfaces with the use of hand and ultrasonic instruments.

Hard tissue measurements were made with the same stent:

1. Crestal level: Inferior margin of the stent to the alveolar crest (Stent-AC).

2. Inferior margin of the stent to the base of the defect (Stent-DB).

3. Alveolar crest to the bottom of the defect (INFRA).

One defect was randomly selected, by the flip of a coin, to be treated with an autogenous bone graft (control), and the other was treated with Ostim (test). All subjects received the test treatment on one defect and the control treatment on the contralateral defect. Autogenous bone chips were retrieved from adjacent areas and packed into the defect. Closure was accomplished using 4-0 silk sutures and a periodontal dressing (Coe-Pak, GC America, IL, USA) was used.

Postoperative care

All subjects received postoperative instructions, includ- ing rinsing with $0.2 \%$ chlorhexidine (twice daily for 2 weeks), and antibiotic and anti-inflammatory systemic medications for 1 week. The patients were re-visited after 7 days for removal of the periodontal dressing and sutures. At the end of 2 weeks and then every month, the patients received professional prophylaxis and oral hygiene reinforcement. Six months after the primary surgery, a reentry surgery was performed. The reentry procedure was aimed at correction of any remaining defects and evaluation of the results of the treatment with reference to the soft and hard tissue parameters. The method of reentry measurements was similar to primary measurements.

\section{Statistical analysis}

The variables are presented as mean \pm standard deviation. The between-group postoperative differences of the defects, before and after the treatment, were compared based on the Wilcoxon test. In addition, MannWhitney $U$ test was used for the comparison of the within-group differences at baseline and 6 months postoperatively. In the present study, $\mathrm{P}<0.05$ was considered to indicate statistical significance.

\section{Results}

A total of 12 patients with 12 pairs of intrabony defects received surgical therapy. A total of 12 sites were treated with autogenous bone graft (ABG), and 12 sites were treated with Ostim. Postoperative healing was uneventful in all cases, and no complications or infections were observed throughout the study period. All subjects returned for re-evaluation after 6 months. During the 6-month period following treatment, all the patients maintained excellent levels of oral hygiene, and plaque and gingival index did not demonstrate any significant differences compared to the baseline values $(\mathrm{P}>0.05)$; (Table 1).

\section{Soft \& Hard tissue parameters}

There were no significant differences in the initial measurements of soft and hard tissue parameters between ABG and Ostim groups (Tables 2 and 3).

Table 1. Mean \pm SD plaque and gingival index scores at baseline and 6-month evaluation.

\begin{tabular}{|c|c|c|c|}
\hline Variables & Baseline & 6 months & P value \\
\hline PI & & & \\
\hline Ostim & $0.6 \pm 0.5$ & $0.5 \pm 0.5$ & 0.500 \\
\hline ABG & $0.8 \pm 0.4$ & $0.5 \pm 0.5$ & 0.375 \\
\hline P value & 0.673 & 1.000 & \\
\hline GI & & & \\
\hline Ostim & $0.9 \pm 0.6$ & $0.5 \pm 0.5$ & 0.063 \\
\hline ABG & $1.0 \pm 0.6$ & $0.5 \pm 0.5$ & 0.063 \\
\hline P value & 0.844 & 1.000 & \\
\hline
\end{tabular}


Table 2. Soft tissue parameters at baseline and after 6 months.

\begin{tabular}{|c|c|c|c|c|c|c|}
\hline Variable & Group & $\begin{array}{c}\text { Baseline } \\
\text { value }(\mathbf{m m})\end{array}$ & $\begin{array}{c}\text { Baseline } \\
\text { comparison }\end{array}$ & $\begin{array}{c}\text { 6-month } \\
\text { value }(\mathrm{mm})\end{array}$ & $\begin{array}{c}\text { Within-group } \\
\text { comparison }\end{array}$ & $\begin{array}{l}\text { Between-group } \\
\text { comparison }\end{array}$ \\
\hline \multirow{2}{*}{ CPD } & Ostim & $6.79 \pm 0.68$ & \multirow{2}{*}{0.551} & $3.58 \pm 0.63$ & $0.002 *$ & \multirow{2}{*}{0.634} \\
\hline & $\mathrm{ABG}$ & $7.37 \pm 1.69$ & & $4.00 \pm 1.38$ & $0.002 *$ & \\
\hline \multirow{2}{*}{ CAL } & Ostim & $10.70 \pm 1.73$ & \multirow{2}{*}{0.319} & $8.08 \pm 1.39$ & $0.002 *$ & \multirow{2}{*}{0.613} \\
\hline & $\mathrm{ABG}$ & $10.08 \pm 2.02$ & & $7.70 \pm 1.94$ & $0.002 *$ & \\
\hline \multirow{2}{*}{ Stent- GM } & Ostim & $4.91 \pm 1.06$ & \multirow{2}{*}{0.179} & $5.00 \pm 1.49$ & 0.713 & \multirow{2}{*}{0.511} \\
\hline & $\mathrm{ABG}$ & $3.62 \pm 0.71$ & & $4.16 \pm 0.86$ & 0.18 & \\
\hline
\end{tabular}

Asterisk indicates statistical significance based on $\mathrm{P}<0.05$.

Table 3. Hard tissue parameters at baseline and after 6 mo.

\begin{tabular}{|c|c|c|c|c|c|c|}
\hline Variable & Group & $\begin{array}{c}\text { Baseline } \\
\text { value }(\mathbf{m m})\end{array}$ & $\begin{array}{c}\text { Baseline } \\
\text { comparison }\end{array}$ & $\begin{array}{c}\text { 6-month } \\
\text { value }(\mathrm{mm})\end{array}$ & $\begin{array}{c}\text { Within-group } \\
\text { comparison }\end{array}$ & $\begin{array}{c}\text { Between-group } \\
\text { comparison }\end{array}$ \\
\hline \multirow{2}{*}{ Stent-AC } & Ostim & $6.95 \pm 1.38$ & \multirow{2}{*}{0.410} & $7.29 \pm 1.72$ & 0.23 & \multirow{2}{*}{0.830} \\
\hline & $\mathrm{ABG}$ & $5.70 \pm 1.13$ & & $5.95 \pm 1.15$ & 0.14 & \\
\hline \multirow{2}{*}{ Stent-DB } & Ostim & $11.12 \pm 1.84$ & \multirow{2}{*}{0.390} & $8.58 \pm 1.95$ & $0.023^{*}$ & \multirow{2}{*}{0.493} \\
\hline & $\mathrm{ABG}$ & $10.54 \pm 2.01$ & & $7.62 \pm 2.06$ & $0.002 *$ & \\
\hline \multirow{2}{*}{ INFRA } & Ostim & $4.16 \pm 0.61$ & \multirow{2}{*}{0.178} & $1.29 \pm 0.54$ & $0.002 *$ & \multirow{2}{*}{0.424} \\
\hline & $\mathrm{ABG}$ & $4.83 \pm 1.40$ & & $1.62 \pm 1.47$ & $0.002 *$ & \\
\hline
\end{tabular}

Asterisk indicates statistical significance based on $\mathrm{P}<0.05$.

Soft tissue parameters are presented in table 2. In comparison with the baseline data, both the test and control groups showed statistically significant differences. Clinical probing depth reduction in the ABG group was $3.37 \mathrm{~mm}(\mathrm{P}<0.002)$ and $3.21 \mathrm{~mm}$ in the Ostim group $(\mathrm{P}<0.002)$. However, the between-group differences after 6 months were not statistically significant $(\mathrm{P}=0$. 634). The clinical attachment gains were $2.38 \mathrm{~mm}$ in the ABG group and $2.62 \mathrm{~mm}$ in the Ostim group. Both the within-group differences were significant $(\mathrm{P}<0.002)$. However, the between-group differences after 6 months were not statistically significant $(\mathrm{P}=0.613)$. An average change of $0.1 \mathrm{~mm}$ in the position of the gingival margin between the baseline and 6-month data was observed in the test group $(\mathrm{P}=0.713)$ and $0.54 \mathrm{~mm}$ in the control group $(\mathrm{P}=0.18)$. In both groups, recession showed a tendency to increase, but the postoperative recession was not affected by the treatment protocol $(\mathrm{P}=0.511)$.

Hard tissue parameters are presented in (Table 3). Evaluation of the crestal resorption found no significant difference for both groups compared to initial measurements. Furthermore, there was no significant difference in crestal resorption in defects treated with Ostim and ABG. An evaluation of the hard tissue findings indicated that both treatment modalities result in defect fill after 6 months. The Ostim group showed $2.54 \mathrm{~mm}(\mathrm{P}=0.023)$ of defect fill, while this was 2.92 in the $A B G$ group $(\mathrm{P}=0.002)$; however, the between-group differences after 6 months were not statistically significant $(\mathrm{P}>0.05)$. Defect resolution was better in the $\mathrm{ABG}$ group $(3.21 \mathrm{~mm}$ ) compared to that in the Ostim group $(2.87 \mathrm{~mm})$. The between-group differences were not statistically significant $(\mathrm{P}=0.424)$.

\section{Discussion}

The present study was designed to determine the effect of ABG and Ostim in the management two and three wall intrabony periodontal defects. These findings seem to be consistent with other research which found the effectiveness of these materials in the treatment of intrabony periodontal defects. At base line, statistical analysis of data revealed no significant differences between the two treatment modalities with regard to gingival index, plaque index and soft and hard tissue measurements, therefore in the end of study the difference between two groups resulted from the type of graft materials.

The probing depth reduced by $3.21 \mathrm{~mm}$ in the ostim site and $3.37 \mathrm{~mm}$ in the ABG site. Decrease in the CAL in the Ostim and ABG Groups were $2.68 \mathrm{~mm}$ and 2.38 $\mathrm{mm}$, respectively. Because the postoperative gingival recession was not significant in both groups suggesting that the gain in attachment is the major contributor to the reduction in the probing depth. 
The intrabony component of the defect in the present study decreased by an average of 2.92 and $2.54 \mathrm{~mm}$ in the ABG and Ostim groups, respectively. The withingroup differences 6 months postoperatively were significant. Because the amount of crestal bone resorption was minimal, these changes mostly reflect the filling of the intrabony defect. The results of this study indicated that ostim treatment was effective in promoting defect fill when compared to presurgical levels.In clinical case series, in which intraoral autogenous grafts were used for the treatment of intrabony periodontal defects, a mean bone fill ranging from 3 to $3.5 \mathrm{~mm}$ was reported $(19,20)$.

The mean bone fill in Froum et al. (19) study using bone blending was $2.98 \mathrm{~mm}$ and in Hiatt et al. (20) study using intraoral cancellous bone was reported $3.5 \mathrm{~mm}$. In this study, the mean bone fill after using ABG was $2.38 \mathrm{~mm}$. The differences between this study and other studies might be attributed to the type of autogenous bone, the type of osseous defects, and the greater initial defect depth. Schwarz et al. (21) evaluated the healing of intrabony peri-implantitis defects following application of two types of hydroxyapatite; a nanocrystalline hydroxyapatite (NHA) or a bovine-derived xenograft in combination with a collagen membrane (BDX1BG). Post-operative wound healing revealed that NHA compromized initial adhesion of the mucoperiosteal flaps in all patients. At 6 months after therapy, showed $0.7 \mathrm{~mm}$ and the mean CAL changed from $7.5-1.0$ to $5.2-0.8$ $\mathrm{mm}$.

The study of Kasaj et al. (22) was designed to compare the clinical outcomes of infrabony periodontal defects following treatment with an anorganic bovine-derived hydroxyapatite matrix/cell-binding peptide (ABM/P15) flow to open flap debridement. Their results demonstrated that 12 months after surgery both treatments resulted in significant $\mathrm{PD}$ reductions and $\mathrm{CAL}$ gains and that treatment with ABM/P-15 in its flow formulation produced enhanced clinical results in terms of PD reductions and CAL gains when compared to open flap debridement alone.

A limitation of clinical regeneration studies, such as the present one, is the inability to assess the histologic characteristics of the repaired tissues. Studies to examine the histologic nature of the interface of a treated bony defect and the root surface are difficult to conduct for ethical reasons.

Another limitation in this study was the sample size. A larger sample size might have demonstrated statistically significant differences between the two groups. Furthermore, the large variability in patient response to therapy created large SDs which limited the ability for statistical analysis to demonstrate differences between the study groups.

Within the limits of the present study, it can be conclud- ed that 6 months after surgery both therapies resulted in statistically significant PD reductions, CAL gains, and bone fill.

\section{References}

References with links to Crossref - DOI

1. Papapanou PN, Tonetti MS. Diagnosis and epidemiology of periodontal osseous lesions. Periodontol 2000. 2000;22:8-21.

2. Mellonig JT, Bowers GM, Cotton WR. Comparison of bone graft materials. Part II. New bone formation with autografts and allografts: a histological evaluation. J Periodontol. 1981;52:297-302.

3. Shirmohammadi A, Chitsazi MT, Lafzi A. A clinical comparison of autogenous bone graft with and without autogenous periodontal ligament graft in the treatment of periodontal intrabony defects. Clin Oral Investig. 2009;13:279-86.

4. Gottlow J, Nyman S, Lindhe J, Karring T, Wennström J. New attachment formation in the human periodontium by guided tissue regeneration. Case reports. J Clin Periodontol. 1986;13:604-16.

5. Lynch SE, Williams RC, Polson AM, Howell TH, Reddy MS, Zappa UE, et al. A combination of platelet-derived and insulin-like growth factors enhances periodontal regeneration. J Clin Periodontol. $1989 ; 16: 545-8$.

6. Trombelli L, Heitz-Mayfield LJ, Needleman I, Moles D, Scabbia A. A systematic review of graft materials and biological agents for periodontal intraosseous defects. J Clin Periodontol. 2002;29 Suppl 3:117-35.

7. Reynolds MA, Aichelmann-Reidy ME, Branch-Mays GL, Gunsolley JC. The efficacy of bone replacement grafts in the treatment of periodontal osseous defects. A

systematic review. Ann Periodontol. 2003;8:227-65.

8. Araújo MG, Sonohara M, Hayacibara R, Cardaropoli G, Lindhe $\mathrm{J}$. Lateral ridge augmentation by the use of grafts comprised of autologous bone or a biomaterial. An experiment in the dog. J Clin Periodontol. 2002;29:1122-31.

9. Khan SN, Cammisa FP Jr, Sandhu HS, Diwan AD, Girardi FP, Lane JM. The biology of bone grafting. J Am Acad Orthop Surg. 2005;13:77-86

10. Pankratov AS, Zuev VP, Alekseeva AN. [The use of hydroxyapatite with ultrahigh dispersity in the combined treatment of patients with mandibular fractures]. Stomatologiia (Mosk). 1995;74:22-5.

11. Bezrukov VM, Grigor'iants LA, Zuev VP, Pankratov AS. [The surgical treatment of jaw cysts using hydroxyapatite with an ultrahigh degree of dispersity]. Stomatologiia (Mosk). 1998;77:31-5.

12. Strietzel FP, Reichart PA, Graf HL. Lateral alveolar ridge augmentation using a synthetic nano-crystalline hydroxyapatite bone substitution material (Ostim): preliminary clinical and histological results. Clin Oral Implants Res. 2007;18:743-51.

13. Thorwarth M, Schultze-Mosgau S, Kessler P, Wiltfang J, Schlegel KA. Bone regeneration in osseous defects using a resorbable nanoparticular hydroxyapatite. J Oral Maxillofac Surg. 2005;63:1626-33. 14. Busenlechner D, Kantor M, Tangl S, Tepper G, Zechner W, Haas R, et al. Alveolar ridge augmentation with a prototype trilayer membrane and various bone grafts: a histomorphometric study in baboons. Clin Oral Implants Res. 2005;16:220-7.

15. Zitzmann NU, Schärer P, Marinello CP. Factors influencing the success of GBR. Smoking, timing of implant placement, implant location, bone quality and provisional restoration. J Clin Periodontol. 1999;26:673-82.

16. Yildirim M, Spiekermann H, Biesterfeld S, Edelhoff D. Maxillary sinus augmentation using xenogenic bone substitute material BioOss in combination with venous blood. A histologic and histomorphometric study in humans. Clin Oral Implants Res. 2000;11:217-29. 17. O'Leary TJ, Drake RB, Naylor JE. The plaque control record. J Periodontol. 1972;43:38.

18. Löe H. The Gingival Index, the Plaque Index and the Retention Index Systems. J Periodontol. 1967;38:610-6.

19. Froum SJ, Gomez C, Breault MR. Current concepts of periodontal regeneration. A review of the literature. N Y State Dent J. 2002;68:14-22. 
20. Hiatt WH, Schallhorn RG. Intraoral transplants of cancellous bone and marrow in periodontal lesions. J Periodontol. 1973;44:194208.

21. Schwarz F, Bieling K, Latz T, Nuesry E, Becker J. Healing of intrabony peri-implantitis defects following application of a nanocrystalline hydroxyapatite (Ostim) or a bovine-derived xenograft (BioOss) in combination with a collagen membrane (Bio-Gide). A case series. J Clin Periodontol. 2006;33:491-9.

22. Kasaj A, Röhrig B, Reichert C, Willershausen B. Clinical evaluation of anorganic bovine-derived hydroxyapatite matrix/cell-binding peptide (P-15) in the treatment of human infrabony defects. Clin Oral Investig. 2008;12:241-7. 